\title{
TECHNOLOGICAL CHOICE AND WORKPLACE INNOVATION: TOWARDS EFFICIENT AND HUMANISED WORK
}

\author{
LA VARIABLE TECNOLÓGICA Y LA INNOVACIÓN EN EL LUGAR DE TRABAJO: \\ HACIA UN TRABAJO EFICIENTE Y HUMANIZADO
}

\author{
Peter R.A. Oeij* \\ Paul T.Y. Preenen \\ Wouter van der Torre \\ Laudry van der Meer \\ Joep van den Eerenbeemt \\ TNO - Netherlands Organisation for Applied Scientific Research \\ *corresponding author: peter.oeij@tno.nl
}

\begin{abstract}
Technology implementation choices in organisations require trade-offs between economic efficiency and decent work. Technology choices are often started top-down, technocratic, and from an efficiency perspective. Social and organisational aspects are seldomly sufficiently considered in this process. Negative consequences both for the people and for the chance of success of the technology implementation are the result. For overseeing and considering both social and organisational aspects in technology implementation choices, an impact choice model of (new) technologies is helpful. This article discusses such a model: TIM (Technology Impact choices Model). TIM is a method that helps organisations and policy makers assess the impact of technological choice for the production of products and services, the design of the organisation of work, and the content of separate functions and jobs.
\end{abstract}

Keywords: Technology impact, workplace innovation, sociotechnics, humanisation of work.

\begin{abstract}
Resumen: La adopción de tecnología por parte de las organizaciones requiere generar un equilibrio entre la eficiencia económica y el trabajo digno. La incorporación de nuevas tecnologías a menudo se inician de arriba hacia abajo, de forma tecnocrática y desde una perspectiva de eficiencia. Los aspectos sociales y organizacionales rara vez son suficientemente considerados en este proceso. Como resultado de ello, las consecuencias son negativas tanto para las personas como para el éxito de la adopción de tecnología. Para supervisar y considerar tanto los aspectos sociales como organizativos en la adopción de tecnología, es útil contar con un modelo de impacto de la variable tecnológica en las organizaciones. Este artículo aborda este modelo: TIM (Technology Impact choices Model), TIM es un método que ayuda a las organizaciones y a los responsables políticos a evaluar el impacto de la variable tecnológica en la producción de productos y servicios, el diseño de la organización del trabajo y el contenido de las distintas funciones y puestos de trabajo.
\end{abstract}

Palabras clave: Impacto tecnológico, innovación en el lugar de trabajo, sociotecnología, humanización del trabajo.

\section{Introduction}

Technological choice often requires a trade-off between economic efficiency and humanised work. Technological choice, however, is usually implemented top-down and based on technocratic arguments putting efficiency central. In such instances social and organisational arguments play a minor role, which both negatively affects the work of employees and the successful implementation of technology (Bijker et al., 2012; Noble, 1984). To include social and organisational aspects of technological choice, the Technology Impact choices Model (TIM) can be applied. TIM is an instrument to assess the impact of technological choice for the production of products (i.e., goods and services), the design of the organisation of work, and the content of

EUROPEAN
PUBLIC SOCIAL
INNOVATION
REVIEW


separate functions and jobs. TIM helps users to make balanced decisions of the implementation of new technology and the future of work. TIM embraces social and democratic dialogue and employee engagement (Ennals, 2018). The design of humanised work could benefit from applying a workplace innovation lens. Workplace innovation incorporates humanised and economic aspects of technological choices, because employee engagement is its hallmark (Oeij et al., 2015).

This article first discusses the essence of workplace innovation and the way strategy, structure and culture are related to the governing management philosophy. Subsequently, TIM will be presented and two examples will be provided how it can be applied for technological choice. Public and private organisations not only have room to manoeuvre when it comes to technological choice, they have a responsibility as well for the consequences of technological choice for employees and the organisation as a whole.

\section{Workplace innovation}

Workplace innovation points to innovative ways how production and work are designed, and thereby stresses new ways of the deployment of persons (Oeij \& Dhondt, 2017). Workplace innovation is not a goal in itself as its purpose is to simultaneously achieve better organisational performance, such as economic targets, and good quality of work, i.e., work that is safe, healthy, challenging and meaningful (so-called 'active jobs' that balance learning opportunities with stress risks; see Karasek, 1979). Workplace innovation further supports the embedment and adoption of new technology in the organisation by employees (Dhondt et al., 2018; Putnik et al., 2019a, 2019b). The hallmark of workplace innovation, employee engagement (Totterdill et al., 2012) by designing 'active jobs' (Oeij \& Dhondt, 2017) is normative, and promotes the humanisation of work. Having said that, practitioners rightly ask: then, please tell me how to do it? Employee engagement, for instance, is to involve employees in the process of change and implementation of (technological) innovations, in ways that gives them voice. After all, when the jobs of employees are going to change, people favour having a certain level of influence or 'control capacity' (De Sitter et al., 1997). Employee engagement and involvement enhances innovation-adoption, and reduces resistance to change and risk-avoiding defensive behaviours, which is not something one can use in the process of innovation. On the contrary, engaging employees can have positive inputs to the innovation process. That process of technological choice will benefit from their knowledge. It will also positively affect the implementation process. Finally, the needed structural and cultural adaptations can benefit from their motivation to contribute. Moreover, employees are largely the end-users of implemented technology, so their adoption of new technology is crucial. For this reason, workplace innovation is a decisive element for successful technological innovation, better performance, and better jobs (Oeij, Dhondt, Rus \& Van Hootegem, 2019).

When applying workplace innovation, it makes sense to distinguish the content from the process of innovation (Oeij, Dhondt, Pot \& Totterdill, 2018). The content or subject is about redesigning the organisation and people's behaviour from a sociotechnics perspective. We will not deal with that issue here (see for example: Achterbergh \& Vriens, 2010; Christis, 2010; De Sitter et al., 1997; Oeij et al., 2017). The process points to the development and implementation of renewal and innovation and is rooted in the conviction of employee engagement and a bottom-up, decentralised approach. Our point of departure is a humanised of humanistic approach to work and labour (Smith, 2017), which means that work is designed such that people can develop their talents, have safe and healthy working conditions, and can be productive as well. Humanised quality of work is the opposite of alienation, degradation, unfreedom and indecency, it nurtures security, equity, individuation and democracy (Herrick \& Maccoby, 1975).

\section{Structure follows strategy, culture follows structure}

While workplace innovation is a means but no goal, the same goes for technological innovation. To understand the context of both types of innovation, and thus technological choices, we should look at the process of designing organisations. How such processes take place informs us about the level of employee engagement and the deployment of human talents. Our line of reasoning is that technological choices follow a trajectory, as they are based on strategic choices of management. Strategic management implies choices about 
organisational structure (i.e., organisation and job design), which, in turn, have implications for the culture of organisations (i.e., leadership styles and organisational behaviour of its members). It was Alfred Chandler (1962) who stated that 'structure follows strategy', to which we would like to add that 'culture follows structure' (Karanika-Murray \& Oeij, 2017). Although the interaction between strategy, structure and culture is a complex matter, for reasons of simplicity we give some linear thinking examples below.

Our assertion is that technological choices affect organisational design, and thus possibilities for employee engagement. From a black-and-white perspective one can view Figure 1 from either a top-down approach or a bottomup approach. Either approach trickles down from the highest level to the lower ones, and helps us to understand how technological choices affect the organisation and its people in terms of humanised work and economic efficiency. Another metaphor used to indicate the contrast between top-down and bottom-up approaches are the twin concepts of centralised bureaucratic organising and decentralised flow-based organising (Christis, 2010; De Sitter et al., 1997; see also Achterbergh \& Vriens, 2010). The point we make here is that both approaches are management philosophies on which strategies are built, and are in fact two extremes on one dimension where managers and their preferential leadership styles can be positioned (Walton, 1985).

Let us suppose that your strategy is to achieve organisational goals by centralised governance, because, for example, it is your conviction that demanded expertise and decision making about investments must be in central hands. Perhaps the goods and services that you produce are rather standardised (such as high volumes), or that the demand is highly predictable (stable market, stable prices), or that workstations in the production process are tightly coupled (high interdependency). Your production system is characterized by jobs and departments that are designed to require only limited employee autonomy. Shop floor leadership styles and employee working behaviour - jointly constituting the organisational culture - tend toward task-oriented performance, which does not require to stimulate employees to think along with management. The supporting HR system in place will seek to select the suitable employees and train them to be a productive labour force. There is no need for high employee involvement or for a high quality of work to achieve the organisational goals. High innovative capability is irrelevant as well. The technological choices this organisation will make, will support the existing strategy, structure and culture and maintain the established order, i.e., the top-down approach. In the case of automation and digitisation, one can think of the purpose to enhance the efficiency by further standardising the production process and eradicating the need for human interventions. Examples of such processes which are minimizing human decision are the automated evaluation of tax declarations, rent subsidy applications, and the mediations of job seekers to suitable work.

Let us suppose you have another strategy. You still want to supply goods and services to your customers in an efficient and effective manner. Instead of central governance you choose to apply a decentral governance mode because you depend on the employees to realize the desired quality. Employees must deploy their heart and brains and you want to motivate them to do so. In economic terms, the strategy might be quite similar to the first example, but the management philosophy is radically different, namely decentralised, more bottom-up, targeted at employee engagement and humanised work, and more democratic decision making. The chosen production system offers opportunities for employee participation. For this purpose the design of jobs and departments includes autonomy for employees, thus enabling decision making about problems at the level where these problems emerge. The coupling of departments and work stations is not too tight, allowing employees to have their own responsibilities. To nevertheless ensure effective coordination, this organisation applies a leadership style that is not only task-oriented, but also targeted at pleasant working relations and social support. As a consequence, employees take more responsibility, communicate openly, all of which is resulting in less misunderstandings and organisational defensiveness such as resistance to change and risk avoidance. The HR system selects the appropriate personnel with the desired attitudes and competencies and supports their development and deployment of talents to the full. The according organisational culture creates enhanced employee involvement. Not only the organisational performance benefits, also the innovative capability, due to the fact that the quality of work - and learning opportunities for employees - aligns with all these goals. Technological choices made in this organisation have the sub goal to maintain employee engagement, i.e., enforce humanised work. 
Automation and digitisation not just make work easier and more comfortable, but leave space for learning opportunities and shop floor level decision making. Such organisations are more resilient and adaptive because their employees are more resilient and dedicated. Employees are being consulted for technological choices and sometimes they co-decide (see examples in Oeij et al., 2015). Gustavsen framed such processes as 'democratic dialogues' (Ennals, 2018).

Our discussion is meant to emphasize that there is always 'strategic choice' (Child, 1997) to balance technological choices with socioorganisational choices, which is why it is of crucial importance to understand the context in which such choices are being made. Obviously, top-down and bureaucratically designed organisations (lacking active jobs and having many interdependencies) will not benefit from the contributions of their employees in the process of technological choice. Perhaps even worse than that, they run the risk of limited organisational performance as well. In contrary, sociotechnics for example (De Sitter et al., 1997) is built on employee engagement which is crucial to improve individual and organisational performance.

\section{Overseeing the impact of technological choices}

Can organisations get a grip on technological choices? Many technologies are seemingly 'unavoidable', such as IT, social media and AI, whereas others are more or less 'necessary' for effective and efficient production of goods and services, such as automation, digitisation, robotization and miniaturisation (nano technology). Technologies like these can be a threat to jobs and people, making work nonchallenging ('digital taylorism'), but also create new opportunities and jobs. It is a widely shared notion that new technology can contribute to remain attractive jobs for lower and middle educated people and an inclusive economy (OECD, 2016; WEF, 2018). Technology can also make work more complex, varied and challenging. Involving employees in the process of technological choice, however, seems conditional to this end.

Figure 1. Structure follows strategy and culture follows structure

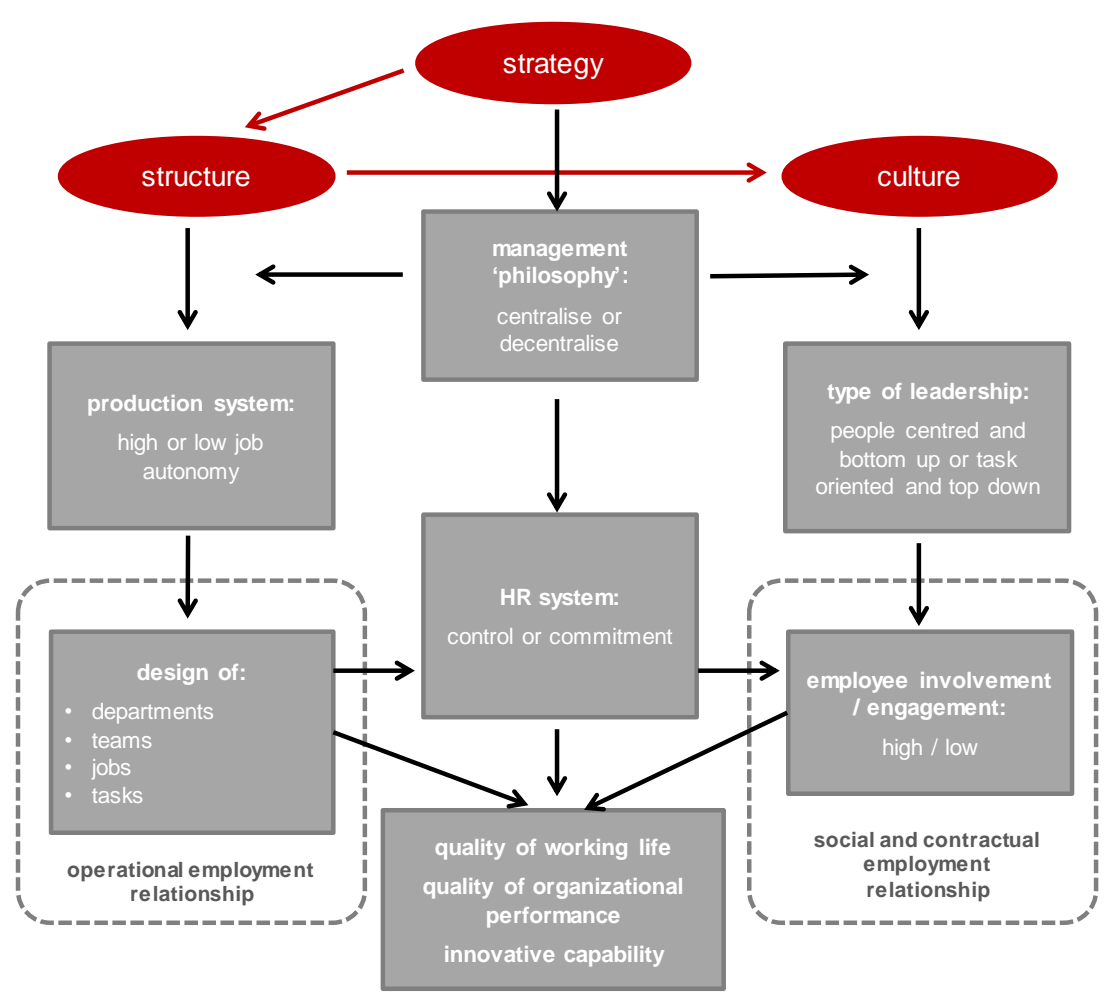

Source: Karanika-Murray \& Oeij, 2017, p. 22. 
TIM is an instrument for making conscious choices to implement new technologies in organisations. A comparative assessment is made of the effects on the organisation of work and on separate functions. The method can be applied to the level of an organisation or to a branch (industrial sector). TIM is based on Technology Impact Assessment, an approved process method to appraise the effects of technology (Van Eijndhoven, 1997), in our case on work and organisation issues. The focus of TIM is to create insights in the consequences of new technology on the process of production of goods and / or services, the organisation of work, jobs and skills / competencies, and HR policy. TIM presupposes (more) democratic decision making in the process of technological choice, and, in so doing, refers to the notion of employee engagement as the hallmark of workplace innovation. The essence of TIM is shown in Figure 2 (Oeij, Preenen \& Van der Torre, 2018).

TIM is a four stage model:

1. The 'technology' step focuses on identifying the coming technologies in the next 5-10 years that may be applied in an organisation (or in your branch). When we used TIM in a company responsible for job matching, the participants were developing ideas for how to apply long distance care (i.e., remote care using tablet devices) might affect the number of specialists who evaluate cases and their replacement by less specialised care givers. Clients would no longer visit the company's premises for face-to-face consults, but simply login to a device (see example 2, 'Job finder', below).
More specifically, to assess step 1 we carry out:

- A web search and literature review of technology forecast and foresight studies;

- Interviews with technology experts;

- An analysis of quantitative data bases (such as patents / IPs and investments in technology).

The result is an overview of technology that is available for the organisation or branch under study.

2. At the 'product / good / service' step the question to answer is whether and how new technology (and if so which technology?) is used to create new or to improve existing goods /services. Further, attention is paid to new technologies (such as IT-software, Big Data, AI, machines / tools) that could be incorporated into the process of production to make the new or improved goods /services (products).

More specifically, this step is being executed by:

- Interviews with leading companies (in the branch) who are known for their innovative technology adoption;

- Interviews with social partners (employer organisations and unions) to assess their position with regard to options for (preferential) technological choice;

Figure 2. Technology Impact Model (TIM)

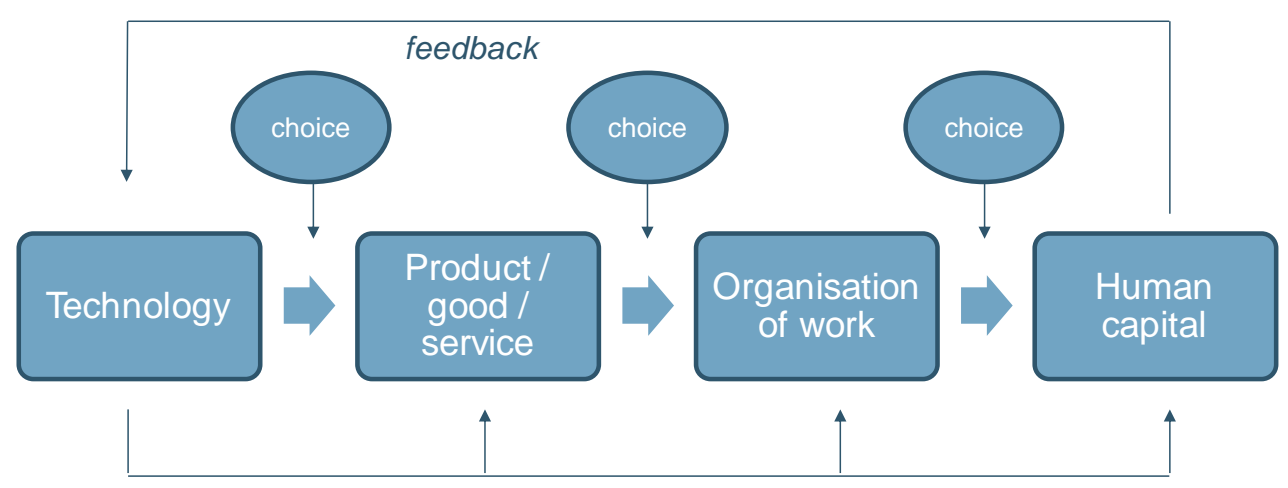

Source: Oeij, Preenen \& Van der Torre, 2018; Oeij, Van der Torre \& Preenen, 2019, p. 292. 
- Interviews with persons from strategy or innovation departments of companies (within the same branch) who are responsible for the innovation of goods / services (products) and / or possess the expertise about new technologies which are of relevance to the company (i.e., IT departments of larger organisations);

- Interviews in SMEs with the general director / manager / owner about strategical options in relation to the innovation of goods / services and the working process and means of production.

The result is an overview of possible technology applications for products, goods or services, meant as a list of options for decision makers at the level of the organisation or the branch.

3. The next step is 'organisation of work' which puts a focus on the division of labour, and firstly pays attention to the design of the process of production. Here TIM looks at the combination of 'technology, organisation \& personnel' (i.e., the TOP-model, Oeij et al., 2006, p. 256). Our normative workplace innovation approach, which is bottom-up, is giving employee engagement a central place. After all, the division of labour with respect to managing tasks (administration, governance, decision making), operating and supporting tasks (the core executing tasks and accounting and clerical work, maintenance, quality control), and how these are divided among management, employees and machines / systems, determine the level of autonomy and learning opportunities of persons. Employee engagement will grow when responsibilities and decision latitude are balanced. Secondly, an investigation takes place how new technology affects the design of departments, teams, functions / jobs and tasks / skills / competencies.

More specifically, this step is executed by carrying out:

- Interviews or workshop with the works council / employees, team leaders, HR and the persons responsible for innovation, about the issue whether the changes on the organisation of the work (i.e. the impact of new technology) can be assessed. For example, which tasks are executed by machines and which by humans, are tasks going to disappear, will new tasks emerge, are tasks going to change?

- Small scale experiments / pilots with newly designed working processes, such as the application of robots or an IT system, to assess aspects like productivity, efficiency, but also stress risks and learning opportunities.

The result is an overview of the impact of technology on work processes, in terms of the division of tasks between humans and technology and an answer to the question how technological changes affect organisational and job design elements.

4. 'Human capital' is the fourth and final step and is targeted at quantitative and qualitative aspects of the deployment of personnel. The implications for combination of tasks into individual jobs and the required skills, the number of staff as the need for skills and talent development play a role, as well as the types of contracts needed, when looking at the required flexibilisation in relation to the unfolding labour market situation (expected labour shortage versus labour surplus). An inventory of all these issues is made to feed the most appropriate HR policy of the organisation.

More specifically, this fourth step is done by:

- Interviews and workshops with HR professionals, line managers and works council / employees to assess the labour market issues and needs;

- The assessment of the impact of technology on changing function profiles or job descriptions. Do we observe tasks within functions to disappear, emerge, change, and can we assess the consequences in terms of newly required competencies and skills?

- Studying relevant labour market and HR literatures to get insight in latest views.

The results answer the question what are the consequences for individual jobs / functions, the skills needed for the functions and what is the required staff after the technology implementation, in terms of number of people, their qualifications, types of contracts and so on. With this knowledge the company must be able to assess its training policy, the mix of types of contracts, and its personnel composition. 
Summarising: to carry out these four steps various external (technology) experts are consulted. Field research is carried out among frontrunner organisations and an inventory is made from stakeholder opinions (e.g., from unions and employer organisations). Applying TIM requires solid cooperation between (internal or external) project members who carry out the analyses, with external experts and internal stakeholders. The process is participatory design to build a 'coalition' about the end result (i.e., coalition approach in Oeij et al., 2006). An elaboration of organising these activities into a project (design) are described elsewhere (Oeij, Van der Torre \& Preenen, 2018).

\section{Choose for workplace innovation and good quality of work}

The preceding steps result in several options for technological choice. There is not 'one best way', on the contrary, there are very many options. Choices can be made by trading off strategic goals against the costs and benefits to achieve the desired goals (Oeij et al., 2011). Our advice is to seek a balance between organisational performance and quality of work (Oeij et al., 2017).

There are quantitative and qualitative inputs and outputs with regard to technological choices. Inputs, for instance, are capital, tools, people and knowledge. Outputs can be satisfied customers, sound organisational performance and profits, and happy and healthy employees. Quantitative aspects, such as money and production volumes, are tangible, whereas qualitative aspects, such as health, safety, using talents, are not; that is the difference perhaps between economic value and public or social value. Nonetheless, all these quantitative and qualitative conditions interact with technological choice. If one strives after employee engagement as an 'intangible' input of the innovation process, it is only logical that it should also be one of the desired outputs. Given that quantitative and qualitative conditions affect to what extent employee engagement can be optimised, choosing a workplace innovation viewpoint means choosing for technologies that can enhance engagement, guarantee humanised work, and imply involving employees in the choice process.

The trade-off of such choices is actually formulating what is the business case that justifies the ultimate chosen technology, bringing together desired economic and social / public values. Our advice is to apply a 'democratic dialogue' along the process (Oeij et al., 2006, p. 258; Oeij et al., 2011; see also Ennals, 2018).

\section{Two cases as examples}

The TIM method is quite new and has not yet been applied extensively. Two examples, however, give a good impression of its usefulness. The first example is a company, anonimised as 'Warehouse' where a choice was made to implement a new automated storage and picking system (Van der Torre \& Krause, 2019). The second example is an exploration of a public service company to digitalise part of the working process in order to combat the shortage of scarce high-skilled professionals, which is anonimised as 'Job finder' (Oeij, Van der Torre \& Preenen, 2019). Although the examples are rather different, this only exemplifies how TIM can be used for different purposes.

\section{Case 1: Warehouse}

TIM is demonstrated in Warehouse, a manufacturer of medical devices such as pacemakers, which are used in interventional medical specialties. The headquarters are in the US, we describe a branch in Europe. This branch is a warehouse of the company's products and parts. Here orders of these products are assembled and prepared for further dispatch.

\section{A. Background:}

The automation and robotization of warehouses goes fast and can help companies and people to be more efficient and flexible. Warehouse wanted to make their logistics order picking process more efficient. However, monetary investments are high, and, moreover, can lead to job loss, and job content and organizational changes. TIM was a relevant way to handle the challenge of implementing technology and decisional make steps visible.

\section{B. TIM steps:}

1. Technology choice / implementation. The growth of work implied the need to extend the warehouse facilities. One option was to physically expand the warehouse. Another one was to use the existing space more efficiently. The latter option seemed more promising because it prevented heavy investments in building a larger warehouse. The solution seemed to use an innovative storage system that would use the present square meters more effectively and 
efficiently. Among the present suppliers this company chose for the AutoStore system. AutoStore is an innovative automatic storage and order picking system. Instead of physically order picking in the warehouse from different places in corridors and scaffoldings where parts are stored, the system brings goods to a person - an order picker - in a compact and efficient way, by using automatic transport bins. A warehouse without automation is made up of scaffolding and corridors. The AutoStore solution requires no corridors. All goods are collected in plastic bins, which stand on top of each other and next to one another in an aluminium grid. Robots ride on top of the aluminium grid. These robots pick up the bins with the desired goods and bring them to the workstations where the order pickers are. Our study was framed around the notion to collect arguments why companies in the logistics branch could choose for sytsems like AutoStore.

The works council was informally involved at an early stage. It was immediately emphasized that cutting jobs was not a goal and that it would not cost losing permanent jobs. The works council received a two-anda-half-day training to learn the system; ergonomic aspects were also covered. The works council could make recommendations to adapt the system, of which a number have been adopted. A demo setup of the AutoStore system was installed for a period of six months in order to make employees acquainted with the innovation at hand. Everyone interested was given an explanation and could ask questions. Eventually, about three-quarters of the employees received such an explanation. In addition, the innovation has been communicated in the company's newsletter. Part of the purpose of the communication was to indicate that cost saving on labour is not the goal and that no people will be fired. Furthermore, it was told that people who wanted to continue working in the old way, were given the opportunity to do so. The implementation period from initial agreement to operations took approximately seven months, and was told to be 'an organically growing process'.

2. Product / good / service. AutoStore allowed a more customized and adaptable service: clients with complex demands could be given better attention which improved better, and quicker service with less mistakes. The innovation is expected to make the service more efficient, fast, accurate and effective, with higher customer satisfaction.

3. Organisation of work. How does AutoStore affect the process? The work inbound and outbound has changed. About a quarter of the storage goes in AutoStore. For the order pickers the big change is that the products come to their workstation instead of going through the warehouse to physically pick parts. AutoStore is a 'goods to person system', which means that the system brings the right products from the warehouse to the order pickers. The work has also become more complex because the (software) system with which they work is more complex than with 'normal' order picking. Whilst the working level is broadly comparable, the order picker must have a better digital background. That can be learned on the job. The jobs requires less carrying and lifting of products and less walking to get parts.

The incoming and outgoing flows of products in the warehouse are handled by the so-called warehouse operator 1,2 and 3 functions. Warehouse operator 3 is the assisting foreman and 1 and 2 are executive employees. There is a job description for AutoStore and zone picking. Most people work in zone picking. New colleagues also start there. The team leaders determine who works where, but order pickers themselves have their preferences and some people are always on the same workstations. But order pickers can rotate over both work processes. While most permanent employees work in both systems one can rotate every other week, every other day, or even for a few hours. Temporary employees who are deployed for a shorter period often do not work in both systems. There is hardly any walking required at AutoStore. Except at the workstations, where the shipping boxes and lists have to be collected and taken away with the use of a cart.

The system is not suitable for all products. The 'fast turners' (products that quickly leave the warehouse, for example, due to shelf life of products), products that are transported in large volumes, and products larger than 60 $\mathrm{cm}$ are stored in the traditional way. The size of the products is important for the size of the bins of the AutoStore system. And for fast turners and large volumes, the traditional way is still more efficient. Three warehouse solutions work side by side now: AutoStore, traditional method of order picking, and bulk storage. 
Tasks of technical departments are extended with Autostore support. Facilities now employ three technicians and an administrative staff who registers the malfunctions. Many minor failures, which were not logged before, provide useful data for system optimization. AutoStore further allows to compose product families which leads to a more efficient distribution of orders between AutoStore and zone picking.

4. Human capital.AutoStore affects two types of personnel. With regard to lower skilled order pickers less staff is needed. Staff, however, is scarce as well at this skill level. The temporary workers who filled a significant number of jobs are less needed, making the company less dependent on such flexible and highly mobile staff. The company supports warehouse personnel who want to grow by offering them additional training from local educational institutes.

The other type of personnel are high skilled engineers who maintain the AutoStore system. Their scarcity remains a serious bottleneck. The most eyecatching human capital issue is the demand for employees who are skilled in technical maintenance and process optimisation, which implies more demand of highly educated IT and technically trained staff. Learning ability of new employees is very important to remain sustainably employable in the context of the introduction of new systems. Besides technical skills, these people need more soft skills, for example working together with the supplier, and experimenting with the demo system, and they must constantly think about how to improve processes. In so doing they are constantly working on innovation and process optimization, enhancing the company's innovative capacity. Skills that employees need, are process thinking, overseeing the bigger picture, being able to identify opportunities for improvement, and problem-solving skills when something goes wrong in the process.

\section{Results:}

After the successful implementation of AutoStore the studied establishment now has a positive image in the eyes of its US mother company. Productivity has increased. The picking frequency has become higher and the walking distances with zone picking have fallen. Pickers no longer need to learn to know where the products are physically, thanks to a software program for which they need limited digital skills to operate. The chance of making mistakes is also smaller with AutoStore. Because the inventory management is included in the work process at AutoStore the inventory matches the registration better. No people on permanent contracts were laid off, and night shifts have been reduced to very special occasions. While all these results in itself are very positive already, the most important saving that has been achieved are avoiding high investments in building a larger warehouse, because this has been prevented by making better use of the existing square and cubic meters. In addition, the analysis gives other companies in the same branch the arguments on which they can base their choice for the AutoStore system.

\section{Case 2: Job finder}

\section{A. Background:}

TIM was applied in an exploratory fashion by a service organisation in job matching. Job finder is a public service organisation in the field of employment. The user wished to first experience the method, preceding potential future technological choices, in order to learn what advantages the method could surface.

The starting point is an experienced labour market shortage of (medical) specialists who assess an employees' working capacity. These are employees who are sick since a longer period or (partly) disabled. As a consequence the organisation has built up arrears in assessments with long waiting times. It is assumed that new technology, and digitisation of the working process, offers opportunities to catch up the backlog.

Therefore, the presented - shorter - example is not a full-fletched TIM analysis, but it can still serve as an illustration. TIM is applied during a half-day workshop to explore technology choices with a group of experts of the organisation. They played the role as a 'project team' responsible for technology choices. It was an idea-generating event. No existing technology products were part of the exercise during this - more or less theoretical - exploration.

\section{B. TIM steps:}

1. Technology choice / implementation. The technology solution that was suggested is an IT application with a self-learning algorithm to make a distinction between types of clients, namely complex versus standard assessments of sick / disabled employees. This would imply that the scarce specialists could be 
working on the complex cases, and the technology would partly process the standard cases. Lower skilled personnel could further process those standard cases.

2. Product / good / service. The service to be developed would become more tailor-made. Clients (employees) with complex problems could be given more attention than clients with standard assessments. The expectation is that applying this IT technology would enhance both effectiveness and efficiency of the working process, and higher client satisfaction. Clients will have shorter waiting times.

3. Organisation of work. The division of labour would result in making the jobs of specialists more challenging and complex. The standard cases, according to the IT algorithm, will be allocated to personnel that is lower skilled and, thus less scarce, contributing to higher efficiency and effectiveness.

4. Human capital. The future HR-strategy will be based on a decreased demand for scarce specialist and a growing demand for lower skilled and less expensive staff. This will reduce the employment policy bottlenecks.

\section{Results:}

The results are only theoretical. Nonetheless, these are evaluated as positive. Moreover, the users also evaluated the usability of the TIM model as applied in the workshop, and stated that the model: 1] provides a structure for facilitating the process and allows for in-depth discussion; 2] is working towards developing a business cases (Oeij et al., 2011), i.e. developing the argumentation why the organisation should invest in the new technology; 3] requires preceding decisions at the strategic level which set the conditions in terms of space for investment and organisational goals. Otherwise making technological choices faces decision constraints at the level of the project team.

\section{Conclusion and recommendation}

Technological choices can be well aligned with workplace innovation goals, such as employee engagement, good quality of work and public / social values. Economic goals, like sound organisational performance and satisfied customers, can be achieved simultaneously with these public / social goals. We outlined the TIM method which can be helpful to contribute to well-balanced decision making about the choice and implementation of new technologies that is including these economic and public / social aspects. Humanised and workplace innovative points of departure create strategies that are conditional to organisational structures that offer decision latitude, and ditto cultures and leadership styles that stimulate people centeredness, transparency and trust. The solution is to have an open eye for employee engagement. In doing so, technological innovation is both successful and social, and workplace innovation can become very concrete and tangible. Humanised work and economic performance can go hand in hand.

The cases we presented differ, in the sense that Warehouse is connected to choosing a concrete new technology, while Job Finder is more an exercise in exploring how technology choices can be approached in a pro-active manner. TIM was applicable in both examples. From the two cases we can conclude that TIM creates insights for users how new technology affects their working processes and what is the impact of the external environment. It helps to make consequences of technology concrete and tangible (case Warehouse), and supports making decisions for the near future when it comes to developing a business case and prepare for labour market issues.

Limitations of the method are that it has not yet been extensively applied and therefore a representative evaluation of TIM is not possible at this stage. While this is certainly a needed task for the future, we can say that the method is rooted in the research and practice of sociotechnics and workplace innovation, for which the evidence is growing that these approaches are beneficial to both organisational performance and quality of jobs (Oeij et al., 2015).

The main recommendation for users of TIM is to take into account how the world of work has changed into a knowledge-based economy, in which the successful mobilisation of good staff depends on how successful employers can meet employees' wishes of challenging jobs. Humanised work is what attracts most employees, in which they can develop their skills and apply their talents. Technological choice should enable humanised work for the jobs that remain, if managers weigh social inclusiveness, organisational performance, good quality jobs, readiness to adopt new technology, and innovative capability among staff as important for the future. 


\section{Acknowledgement}

This contribution is an elaborated and translated version of an article first published in the Dutch language (Oeij, P.R.A., Van der Torre, W., \& Preenen, T.Y.P. 2019).

\section{References}

Achterbergh, J. \& Vriens, D. (2010). Organizations. Social systems conducting experiments. $\left(2^{\text {nd }}\right.$ ed.; $1^{\text {st }}$ ed. 2009). Berlin: Springer.

Bijker, W.E., Hughes, T.P., \& Pinch, T.J. (2012). The social construction of technological systems: New directions in the sociology and history of technology. Massachusetts: MIT Press.

Chandler, A. D. (1962). Strategy and structure: chapters in the history of American industrial enterprises. Boston, MA: MIT Press.

Child, J. (1997). Strategic choice in the analysis of action, structure, organizations and environment: Retrospect and prospect. Organization Studies, 18 (1), 43-76. DOI: https://doi.org/10.1177/017084069701800104

Christis, J. H. P. (2010). Organization and job design: what is smart organizing? In H. A. M. van Lieshout, L. Polstra, J. H. P. Christis and B. J. M. Emans (Eds.), Management of labour. Societal and managerial perspectives (pp. 39-71). Groningen: Hanzehogeschool Groningen University of Applied Sciences.

De Sitter, L. U., Den Hertog, J. F., \& Dankbaar, B. (1997). From complex organizations with simple jobs to simple organizations with complex jobs. Human relations, 50(5), 497-534. DOI: https://doi.org/10.1177/001872679705000503

Dhondt, S., Preenen, P., Oeij, P.R.A., Putnik, K., Torre, W. van der, \& Vroome, E.M.M. de. (2018). Bewältigung technologischer und personeller Herausforderungen in der niederländischen Logistikbranche: Die Bedeutung von Workplace Innovation. In R. Kopp \& P. Ittermann (Red.). Konzeptionelle Perspektiven von Arbeit in der digitalisierten Logistik. Soziologisches Arbeitspapier, 55(pp. 56-75). Dortmund: Technische Universität Dortmund.

Ennals, R. (2018). Democratic dialogue and development: an intellectual obituary of Björn Gustavsen. European Journal of Workplace Innovation, 4 (1), 11-26.

Herrick, N. Q., \& Maccoby, M. (1975). Humanizing work: A priority goal of the 1970's. In: L. E. Davis and A. B. Cherns (eds.), The quality of working life. I (pp. 64-66). New York: Free Press.

Karanika-Murray, M., \& Oeij, P.R.A. (2017). The role of work and organisational psychology for workplace innovation practice: From short-sightedness to eagle view? In European Work and Organisational Psychology in Practice. Special Issue on Workplace Innovation, 1, 19-30.

Karasek Jr, R. A. (1979). Job demands, job decision latitude, and mental strain: Implications for job redesign. Administrative Science Quarterly, 24(2), 285-308. DOI: https://www.jstor.org/stable/2392498

Noble, D.F. (1984). Forces of production: A social history of industrial production. New York: Knopf.

OECD. (2016). The risk of automation for jobs in OECD countries: A comparative analysis. OECD Social, Employment and Migration Working Papers, No. 189. Paris: OECD Publishing. Available at: http://dx.doi.org/10.1787/5jlz9h56dvq7-en (accessed 24 April 2019).

Oeij, P. R. A., De Looze, M. P., Ten Have, K., Van Rhijn, J. W., \& Kuijt-Evers, L. F. M. (2011). Developing the organization's productivity strategy in various sectors of industry. International Journal of Productivity and Performance Management, 61(1), 93-109. DOI: https://doi.org/10.1108/17410401211187525 
Oeij, P.R.A., \& Dhondt, S. (2017). Theoretical approaches supporting workplace innovation. In P.R.A. Oeij, D. Rus, F.D. Pot (Red.), Workplace Innovation: Theory, Research and Practice (pp. 63-78), Series 'Aligning Perspectives on Health, Safety and Well-Being'. Cham: Springer.

Oeij, P. R. A., Dhondt, S., Pot, F., \& Totterdill, P. (2018). Workplace innovation as an important driver of social innovation. In J. Howaldt, C. Kaletka, A. Schröder, \& M. Zirngibl (Eds.), Atlas of social innovation - new practices for a better future (pp. 55-57). Dortmund: Sozialforschungsstelle, TU Dortmund University.

Oeij, P.R.A., Dhondt, S., Rus, D., \& Van Hootegem, G. (2019). The digital transformation requires workplace innovation: an introduction. International Journal of Technology Transfer and Commercialisation, 16(3), 199-207.

Oeij, P.R.A., Preenen, P., \& Torre, W. van der. (2018). Technology Impact Assessment. Een aanpak om de impact van technologie op werk in kaart te brengen op organisatie en individueel niveau. Leiden: TNO (in Dutch).

Oeij, P.R.A., Rus, D., \& Pot, F.D. (Eds.). (2017). Workplace Innovation: Theory, Research and Practice, Series 'Aligning Perspectives on Health, Safety and Well-Being'. Cham: Springer.

Oeij, P.R.A., Torre, W. van der, \& Preenen, T.Y.P. (2019). Technologiekeuzen en sociale innovatie: naar efficiënte en menswaardige arbeid. In: STAD 2019: Technologische en sociale innovatie bij de overheid. Gevolgen voor beleid, bestuur en management (pp. 285-298). Staat van de Ambtelijke Dienst (STAD). Publikatiereeks Overheid \& Arbeid, 2019, Nummer 50. Den Haag: CAOP.

Oeij, P. R. A., Wiezer, N. M., Elo, A. L., Nielsen, K., Vega, S., Wetzstein, A., \& Żołnierczyk, D. (2006). Combating psychosocial risks in work organisations: Some European practices. In: S. McIntyre and J. Houdmont (eds.), Occupational health psychology: European perspectives on research, education and practice, 1, (pp. 233-263). Castelo da Maia, Portugal: ISMAI Publishers.

Oeij, P.R.A., Žiauberytė-Jakštienė, R., Dhondt, S., Corral, A., Totterdill, P., \& Preenen, P. (2015). Workplace Innovation in European companies. Study commissioned by Eurofound, Programme 'Third European Company Survey'. Luxemburg: Publications Office of the European Union.

Putnik, K., Oeij, P., Dhondt, S., Van der Torre, W., De Vroome, E., \& Preenen, P. (2019a). Innovation adoption of employees in the logistics sector in the Netherlands: The role of workplace innovation. Submitted for publication to European Journal of Workplace Innovation.

Putnik, K., Oeij, P., van der Torre, W., de Vroome, E., \& Dhondt, S. (2019b). Innovation adoption of employees in logistics: Individual and organisational factors related to the actual use of innovation. International Journal of Technology Transfer and Commercialisation, 16(3), 251-267.

Smith, N. H. (2017). Arendt's anti-humanism of labour. European Journal of Social Theory, 22(2), 175-190. DOI: https://doi.org/10.1177/1368431017746326

Totterdill, P., Cressey, P., \& Exton, R. (2012) Social innovation at work: workplace innovation as a social process. In: H-W. Franz, J. Hochgerner, \& J. Howaldt (Eds.), Challenge Social Innovation. Potential for Business, Social Entrepreneurship, Welfare and Civil Society, (pp.241-259). Berlin: Springer.

Van der Torre, W. \& Krause, F. (2019). The impact of goods-to-person systems on the tasks and skills of warehouse operators and engineers. Ongoing TKI Dinalog project "Human and robot: working together in the warehouse". Available at: https://www.dinalog.nl/project/mens-en-robot-magazijn/ (in Dutch).

Van Eijndhoven, J. C. (1997). Technology assessment: Product or process? Technological Forecasting and Social Change, 54(2-3), 269-286. DOI: https://doi.org/10.1016/S0040-1625(96)00210-7

Walton. R. (1985). From Control to Commitment in the Workplace. Harvard Business Review, 63(4), 77-84.

World Economic Forum. (2018, September). The Future of Jobs Report 2018. Insight Report. Retrieved from WEF. 